Available online at GSC Online Press Directory

GSC Biological and Pharmaceutical Sciences

e-ISSN: 2581-3250, CODEN (USA): GBPSC2

(RESEARCH ARTICLE)

\title{
Schistosomiasis among primary school pupils in Pilgani Distric, Langtang North Local Government Area, Plateau State, Nigeria
}

\author{
Dawet Anthony 1, ${ }^{*}$, Bulus Emmanuel ${ }^{1}$, Joachim Blessing N ${ }^{1}$, Lumi Enock B ${ }^{2}$ and Yakubu David P 1 \\ ${ }^{1}$ Department of Zoology, Faculty of Natural Sciences, University of Jos, P.M.B. 2084, Jos, Plateau State, Nigeria. \\ 2 Department of Science Laboratory Technology, Faculty of Natural Sciences, University of Jos.
}

Publication history: Received on 19 July 2019; revised on 21 August 2019; accepted on 5 September 2019

Article DOI: https://doi.org/10.30574/gscbps.2019.9.1.0135

\begin{abstract}
Schistosomiasis caused chronic infection which can affect all aspects of a person's health and learning especially among school children. This study was carried out to determine the prevalence of schistosomiasis among school children in Pilgani District, Langtang North LGA, Plateau State. Two prelabeled specimen bottles were given to each school pupil for stool and urine samples collection. The stool samples were prepared using formal-ether concentration technique and examined for Schistosoma mansoni while the urine samples were centrifuged and the deposits was examined for $S$. haematobium. Reagent strips were used to detect microhaematuria and proteinuria in the urine samples. Out of the 284 school pupils examined, 70 (24.65 \%) were infected among which 56(31.83\%) were males and $14(12.96 \%)$ were females. The age group 15 - 16 had the highest infection (38.89\%) while children within age group $5-6$ had the least infection (11.76\%). Pupils that used streams as their source of water had the highest infection but no infection was recorded among children using borehole water. There was significant $(\mathrm{P}<0.05)$ difference in the prevalence of the disease according to age, sex and sources of water used. The presence of microhaematuria and proteinuria was recorded in $21.13 \%$ and $16.20 \%$ respectively of the pupils examined. Inadequate numbers of latrines with bad sanitation were the main risk factors associated with the disease transmission. A control program to decrease the prevalence and intensity should be implemented in this area to improve health status of the community.
\end{abstract}

Keywords: Schistosomiasis; Infection; School-age children; Pilgani; Plateau State

\section{Introduction}

Schistosomiasis is an infectious disease caused by blood flukes (trematode worms) of the genus Schistosoma. Fresh water snails are also infected by this parasite during its life cycle, and humans that come into contact with fresh water that contains these snails are at risk for infection. Seven hundred million people are at risk in 74 countries, and 240 million are already infected. Schistosomiasis ranks second only to malaria as the most common parasitic disease, and are the most deadly NTD, killing an estimated 280,000 people each year in the African region alone [1].

The disease is prevalent in tropical and subtropical areas, especially in poor communities without access to safe drinking water and adequate sanitation. Estimates show that at least 206.4 million people required preventive treatment for schistosomiasis in 2016 and at least $91.4 \%$ of those requiring treatment for schistosomiasis live in Africa [2]. School-age children who live in these areas or immigrants who are exposed to contaminated freshwater, are often most at risk because they tend to spend time swimming or bathing in water containing infectious cercariae [https://www.cdc.gov/parasites/schistosomiasis/epi.html Last accessed on 26/12/2018 4.56 am]

\footnotetext{
${ }^{*}$ Corresponding author

E-mail address: thonydawet@gmail.com
} 
Although the worms that cause schistosomiasis are not found in the United States, people are infected worldwide [https://www.cdc.gov/parasites/schistosomiasis/ Last accessed on 26/12/2018 5.16am]. An estimated 25 million people are at risk of contracting schistosomiasis in the Americas; 90\% of them are in Brazil. It is estimated that 1.6 million school-age children need preventive pharmacological treatment (with praziquantel), primarily in Brazil and Venezuela [3]. Berry et al. [4] reported a single case of acute infection of urinary schistosomiasis probably acquired through bathing in the Cavu River in Corsica, France in summer 2015. Grobusch, et al. [5] reported that out three hundred and thirty three reports of schistosomiasis analyzed for epidemiologic and clinical features, majority [53\%] of the patients were of European origin. In a European surveillance program of imported infectious diseases between 1998-2010 using an electronic reporting system of the 1587 individuals with diagnosis of schistosomiasis 1465 were eligible for analysis, 486 (33\%) were classified as Europeans, 231 [16\%] as Expatriates and 748 [51\%] as nonEuropeans. [6].

In Africa with the highest infection, the overall prevalence of $25.6 \%$ intestinal schistosomiasis was reported in school children in White Nile State, Sudan [7]. A 2018 research report released by Makerere University School of Public Health indicates that $29 \%$ of 40 million Ugandans are infected by bilharzia, which translates into about 12 million people suffering from the disease. The research findings say the burden is up to $42 \%$ among children aged between 2 and 4, posing a huge risk to their health. [<https://www.monitor.co.ug /Special Reports/Bilharzia-infections-hit- $12 \mathrm{~m}$ Ugandans-report/688342-5190618-x7tnh4/index.html>Last accessed on 12/07/2019 12.47am].

Studies in Nigeria showed that the disease is still a challenge in various parts of the country. Abdulkareem et al. [8] in their studies on urinogenital schistosomiasis among school-aged children in three selected rural communities in Kwara State reported the prevalence of 45.6\%. $17.8 \%$ was reported among Hausa communities in five rural areas of Kano State [9]. $21.5 \%$ of school-aged children from three Local Government Areas in Benue State were infected with Schistosoma haematobium [10]. Nwabueze and Opara [11] reported that urinary schistosomiasis among School Children in Riverine Communities of Delta State, Nigeria significantly increased from $21.7 \%$ in 2003 to $91.4 \%$ in 2004. The PCR amplification of Dra1 gene from the from the urine and blood samples showed that of the 63 participants in Apojula, a neglected community located around Oyan Dam, near Abeokuta, Ogun state southwest Nigeria, confirmed that 59 (93.65\%) and 62 (98.4\%) were infected respectively with S. haematobium [12].

Plateau State ranked twelfth among the fourteen States in Nigeria that were hyperendemic with prevalence of $>50 \%$ urinary schistosomiasis with Ogun and Ekiti being the first and second rank respectively [13]. The prevalence of 2.07 $\%$ was reported in Gwong and Kabong areas in Jos North LGA, Plateau State [14]. The result of pre and post treatment of school age children in Langai District, Mangu LGA, Plateau State showed the prevalence of $6.4 \%$ urinary schistosomiasis [15]. Istifanus et al. [16] reported the prevalence of $15.83 \%$ intestinal schistosomiasis among some inhabitants of Bassa LGA, Plateau State, Nigeria.

The disease can affect different parts of the body, including the lungs, the nervous system, and the brain. The area of damage will depend on the species of parasite. Bilharzia is not usually fatal immediately, but it is a chronic illness that can seriously damage the internal organs. In children, it can lead to reduced growth and problems with cognitive development [17]. Children who are repeatedly infected can develop anemia, malnutrition, and learning difficulties. After years of infection, the parasite can also damage the liver, intestine, spleen, lungs, and bladder [1]. Brazil, which has the largest population at risk of the disease in America, has a schistosomiasis control program that includes mass treatment in communities with more than $25 \%$ prevalence as well as active case finding and selective treatment of families in areas with lower prevalence, along with other control measures [18].

\section{Material and methods}

\subsection{Study area}

The study was carried out in Pil-gani district, Langtang North Local Government Area, located in the Southern zone of Plateau State, Nigeria. Pil-gani district is made up different communities and transverse by many rivers and streams which are sources of water for domestic and recreational purposes. The average temperature was $31^{\circ} \mathrm{C}$ with rainfall of $1413 \mathrm{~mm}$ between April and October. Farming was the major occupation in the area, some of the crops cultivated in this area include: rice, maize, guinea corn, groundnut, pepper among others. The sanitary system was mostly pits toilets, but most people defecated and urinated in an open land thereby enhancing the transmission of schistosomiasis. 


\subsection{Study population}

This consists of primary schools pupil between ages $5-16$ among classes $1-6.284$ school pupil from five out of nineteen schools were randomly selected. School pupils who agreed to participate in the research were randomly selected to provide their urine and stool samples.

\subsection{Ethical approval}

Before the commencement of the study, ethical approval was obtained from Langtang North Local Government Education authority. Informed consent was also obtained from the parent or guardian of the pupils in the primary schools.

\subsection{Inclusion criteria}

This include pupils in the selected primary schools whose guardian/parent consented that their children should be part of the study.

\subsection{Samples collection}

Two wide-mouthed, screw-capped, pre-numbered, sterilized plastic containers were given to each person to collect the stool and urine samples. For urine, they were instructed to collect midstream urine not less than an estimated volume of $10 \mathrm{ml}$ and have the last drops of the urine passed included in the bottles. The last drops often content the highest number of eggs [19].The urine samples along with the stool samples were taken to the laboratory in ice-block packed coolers where they were processed and examined. A personal data form was used to obtain the following: serial number, sex, age, school and source of drinking water.

\subsection{Microscopic examination of the urine samples}

During the investigation in the laboratory, the following steps were followed. The centrifuge tubes were labelled with the sample numbers and an equal volume of urine samples were transferred into each tube. The tubes were set to ten thousand revolutions per minutes $(10,000 \mathrm{rpm})$ for five minutes. After the centrifugation, the tubes were removed from the centrifuge machine and the supernatants were discarded, leaving only the deposits at the bottom of the tubes. Unto a clean grease-free slide, a drop of the detached deposit was dropped and covered with a cover slip gently without the formation of air bubbles. The slide was then mounted on the microscope stage and viewed for the presence of $S$. haematobium ova using x10 and x40 objective lenses [20].

\subsection{Detection of microhaematuria and proteinuria by urinalysis}

Urinalysis was done with reagent strip Meditest combi-9, manufactured by Machery-Nagel. The manufacture's test instruction were strictly followed to detect microhaematuria and proteinuria in the urine sample. The strip was gently removed from its container and there was directional arrow marked on the strip. The strip was dipped into the urine sample and allowed to get wet. The strip was read by comparing with the standard on the back of the container within 2 minutes and reported. [21].

\subsection{Examination of stool for eggs}

To detect the eggs of $S$. mansoni, qualitative and quantitative analyses were carried out. For direct qualitative examination, the stool samples were first homogenized with an applicator. A light emulsion, of the homogenized stool was made on the slide with normal saline using an applicator, covered gently with a cover slip. This was subsequently examined microscopically using $\mathrm{x} 10$ and $\mathrm{x} 40$ objectives. For quantitative method, the formal-ether concentration technique as described by [19] was adopted. One [1] gram of sample was placed in a test tube and drops of normal saline were added and emulsified thoroughly, $7 \mathrm{ml}$ of $10 \%$ formal-saline was added and was mixed thoroughly and $3 \mathrm{ml}$ of ether was added and covered with a rubber bank, and shaken vigorously and centrifuge at 3000 rmp for $3 \mathrm{~min}$, the supernatant was discarded and deposit examined using x10 and x40 objectives.

\subsection{Statistical analysis}

Data were analyzed using chi-square method where $p<0.05$ was considered significant. 


\section{Results}

\subsection{Results of parasitological examination}

Out of the 284 pupils examined for both Urinary and Intestinal Schistosomiasis, 70[24.65\%] were infected among which $44[15.49 \%]$ were found to be infected with S. haematobium while 26[9.15\%] had S. mansoni.

Table 1 shows the prevalence of schistosomiasis in the five primary schools. Zamadede primary school had the highest infection 18 [36.00\%], followed by Pishe primary school 16[26.66\%], Ganglang primary school 14[23.33\%] and Bobo primary school $12(21.43 \%)$ while Pangfi primary school had the least infection 10 [17.24\%]. There was no significant [p>0.05] difference in infection between the schools.

Table 1 Prevelance of Schistosomiasis According to Schools

\begin{tabular}{llcccc}
\hline S/N & School & No. Examined & No. Infected [\%] & df & P.value \\
\hline 1 & LGA Pr. School Pangfi & 58 & $10[17.24]$ & & \\
2 & LGA Pr. School Zamadede & 50 & $18[36.00]$ & & \\
3 & LGA Pr. School Ganglang & 60 & $14[23.33]$ & 4 & 0.224 \\
4 & LGA Pr. School Pishe & 60 & $16[26.66]$ & & \\
5 & LGA Pr. School Bobo & 56 & $12[21.43]$ & & \\
& Total & 284 & $70[24.65]$ & & \\
\hline
\end{tabular}

Table 2 shows the prevalence of infection according sexes. This result shows that males were more infected than females. Out of the 176 males examined, 56 [31.82\%] were infected while 14[12.96\%] of the 108 females examined were infected. 21[11.93\%] males and 5[4.63\%] females were found to be infected with S. mansoni, while 35[19.89\%] males and 9[8.33\%] females were infected with S. haematobium. However, there was a significant [P<0.05] difference in schistosomiasis infection between the sexes.

Table 2 Prevelance of Schistosoma Species According to Sex

\begin{tabular}{lcccccc}
\hline \multirow{2}{*}{ Sex } & \multirow{2}{*}{ No. Examined } & \multicolumn{2}{c}{ No. Infected with } & \multirow{2}{*}{ Total [\%] } & df & P.value \\
\cline { 3 - 4 } & & S. mansoni [\%] & S. haematobium [\%] & & & \\
\hline Male & 176 & $21[11.93]$ & $35[19.89]$ & $56[31.82]$ & & \\
Female & 108 & $5[4.63]$ & $9[8.33]$ & $14[12.96]$ & 1 & 0.019 \\
Total & 284 & $26[9.15]$ & $44[15.49]$ & $70[24.65]$ & & \\
\hline
\end{tabular}

The age related prevalence of schistosomiasis among primary schools pupils in Pil-gani district, Langtang North is shown in [Table 3]. The highest prevalence was recorded in age group 15-16 which had 14(38.89\%) pupils infected, followed by age group 13-14 with 17 [34\%], age group 11-12 with 12[27.91\%], age group 9-10 with 9[21.95\%], age group 7-8 with $10[21.74 \%]$ while age group 5-6 with $8[11.76 \%]$ had the least infection. The prevalence of schistosomiasis in the study area was significantly $[\mathrm{p}<0.05]$ different among the age groups.

The highest infection of 37[49.33\%] was recorded in pupils using stream as source of drinking water followed by those using dam with 9[29.03\%], then those using river with 20[22.47\%], and those using well with 4[9.09\%] while no infection was recorded among pupil using borehole [Table 4]. However, there was a significant [P<0.05] difference in the infection according to sources of water. 
Table 3 Prevalence of Schistosomiasis According to Age Groups.

\begin{tabular}{cccccc}
\hline Age & No. Examined & No. Infected & Percentage [\%] & df & P. value \\
\hline $5-6$ & 68 & 8 & 11.76 & & \\
$7-8$ & 46 & 10 & 21.74 & & \\
$9-10$ & 41 & 9 & 21.95 & 5 & 0.024 \\
$11-12$ & 43 & 12 & 27.91 & & \\
$13-14$ & 50 & 17 & 34 & & \\
$15-16$ & 36 & 14 & 38.89 & & \\
Total & 284 & 70 & 24.65 & \\
\hline
\end{tabular}

Table 4 Prevalence of Schistosomiasis According to Sources of Drinking Water

\begin{tabular}{lccccc}
\hline Sources of Drinking Water & No. Examined & No. Infected & Percentage [\%] & df & P. value \\
\hline Borehole & 45 & 0 & 0.00 & & \\
Well & 44 & 4 & 9.09 & & \\
Dam & 31 & 9 & 29.03 & 4 & 0.000 \\
River & 89 & 20 & 22.47 & & \\
Stream & 75 & 37 & 49.33 & & \\
Total & 284 & 70 & 24.65 & & \\
\hline
\end{tabular}

The various species of parasites observed from the pupils are shown in table 5. S. haematobium were the parasite with the highest infection 44 [15.49\%], followed by S. mansoni with 26[9.15\%], Taenia with 16[5.63\%], Ascaris species with 14[4.93\%], Hookworm species with 12[4.23\%] and Fasciola species had the least infection of 4[1.41\%].

Table 5 Parasite species Distribution among the Pupils in the Study Area.

\begin{tabular}{lcc}
\hline \multicolumn{1}{c}{ Species of Parasite } & No. Infected (N=284) & Percentage [\%] \\
\hline S. mansoni & 26 & 9.15 \\
S. haematobium & 44 & 15.49 \\
Ascaris species & 14 & 4.93 \\
Hookworm species & 12 & 4.23 \\
Fasciola species & 4 & 1.41 \\
Taenia species & 16 & 5.63 \\
\hline
\end{tabular}

\subsection{Results for microhaematuria and proteinuria}

The relationship between Microhaematuria and S. haematobium [Table 6] shows that out of the 284 pupils examined, $60[21.13 \%$ ] tested positive for microhaematuria. However, 31[70.45\%] out of the 44 infected with S. haematobium tested positive for microhaematuria [sensitivity] while 13[29.55\%] of the infected tested negative for 
Dawet et al. / GSC Biological and Pharmaceutical Sciences 2019, 09(01), 005-014

microhaematuria [false negative]. Furthermore, 29[12.08\%] out of the 240 uninfected tested positive for microhaematuria while 211[87.92\%] uninfected tested negative for microhaematuria [specitifity].

Table 6 The Prevalence of S. haematobium and Microhaematuria in the Study Area

\begin{tabular}{|c|c|c|c|c|c|}
\hline Microhematuria & $\begin{array}{l}\text { No. Infected with } \\
\text { S. haematobium [\%] }\end{array}$ & $\begin{array}{l}\text { No. uninfected with } \\
\text { S. haematobium [\%] }\end{array}$ & Total [\%] & df & P. value \\
\hline Positive & $31[70.45]$ & $29[12.08]$ & $60[21.13]$ & & \\
\hline Negative & $13[29.55]$ & $211[87.92]$ & 224 [78.87] & 1 & 0.000 \\
\hline Total & $44[100.00]$ & $240[100.00]$ & 284 [100] & & \\
\hline
\end{tabular}

Table 7 shows that out of the 284 urine samples collected, 46[16.20\%] were positive for proteinuria. This goes further to revealed that 29 [65.91\%] out of the 44 pupils infected with urinary schistosomiasis tested positive for proteinuria [sensitivity] while 15[34.09\%] tested negative [false negative]. However, 17[7.08\%] out of the 240 uninfected pupils tested positive for proteinuria while 223[92.92\%] tested negative for proteinuria [specitifity].

Table 7 Prevalence of S. haematobium and Proteinuria in the Study Area

\begin{tabular}{llllll}
\hline Proteinuria & $\begin{array}{l}\text { No. Infected with } \\
\text { S. haematobium [\%] }\end{array}$ & $\begin{array}{l}\text { No. Uninfected with } \\
\text { S. haematobium [\%] }\end{array}$ & Total [\%] & df & P. value \\
\hline Positive & $29[65.91]$ & $17[7.08]$ & $46[16.20]$ & & \\
Negative & $15[34.09]$ & $223[92.92]$ & $238[83.80]$ & 1 & 0.000 \\
Total & $44[100.00]$ & $240[100.00]$ & $284[100]$ & & \\
\hline
\end{tabular}

\section{Discussion}

The overall prevalence (24.65\%) of schistosomiasis in this area shows that the disease is a challenge to the inhabitants even though it was moderate. The results of this study is consistent Onwe et al. [22] who recorded $22.7 \%$ infection in children examined in the six of the seven primary schools surveyed in Ebonyi North. The prevalence of $S$. haematobium [15.49\%] recorded in this study agrees with the $16.4 \%$ urinary schistosomiasis reported in Katsina-Ala LGA, Benue State [23]. The prevalence of S. Mansoni [9.15 \%] in this study was slightly lower than the $15.8 \%$ in some inhabitants of Bassa LGA [16]. The moderate rate in this study could probably be due to awareness by parents and children in this community and prompt treatment of infected persons having known the economic effects on a farming community. The overall prevalence recorded in this study was lower than the $42.7 \%$ urinary schistosomiasis reported in Kano [24], $54 \%$ urinogenital schistosomiasis in Nkalagu community, Ebonyi State [25] and 65 \% urinary schistosomiasis in Ikpeshi community, Edo State [26]. This variation in infection could probably be due to differences in water contact and other human activities that made some pupil more exposed to the risks of the infecting the parasites than others.

The higher prevalence [15.49\%] of S. haematobium than S. mansoni [9.15\%] recorded in this study is consistent with $12.9 \%$ and $2.95 \%$ respectively in Khartoum, Sudan [27]; $44.3 \%$ and $3.4 \%$ respectively in Gadabuke, Toto LGA, Nassarawa State [28]. Nigeria ranks highest in terms of schistosomiasis burden among the countries in sub-Saharan Africa of the 192 million cases estimated in sub-Sahara, Nigeria alone has 29 million cases. Urinary schistosomiasis accounts for more than $90 \%$ of all schistosomiasis cases in Nigeria [13]. The high prevalence of Schistosoma infections than other parasites species recorded among the school pupils in this study is consistent with Mugono et al. [29] who reported high prevalence of intestinal schistosomiasis [63.91\%] than soil transmitted helminths [6,73\%] with the prevalence species of Hookworm being $5.69 \%$ and Ascaris lumbricoides $1.03 \%$ proving that schistosomiasis infection is dorminant amongs other infections. Munisi et al. [30] also recorded a higher prevalence of S. mansoni $84.01 \%$ than $1.4 \%$ hookworm and Ascaris lumbricoides each in Rorya District, Mara region, Northwestern Tanzania. The prevalence was higher in LGA Primary school Zamadede 18[36.00\%], followed by LGA Primary school Pishe 16[26.60\%] while LGA Primary school Pangfi had the least infection [17.24\%]. The variations in the infections 
according to schools could be due to the availability of streams and other sources of infection in communities where the infection was higher.

The high prevalence recorded in males in this study than females agrees with Ladan et al. [31] who recorded the prevalence of $56.41 \%$ in males and $31.38 \%$ in females in selected villages near a dam site in Gusau LGA, Zamfara State, Nigeria. Higher prevalence in males than females: $50 \%$ and $38 \%$ in males and females respectively [28]; $36 \%$ and $18 \%$ [24]; $27.5 \%$ and $17.5 \%$ [22]; $50.8 \%$ and $42.4 \%$ [8] were reported from studies in other areas. Hajissa et al., [27] also reported higher prevalence [60\%] of $S$. mansoni in males than females [40\%] but in the case of $S$. haematobium, both genders were equally infected (50\%). Ishaleku et al. [32] also reported equal infections with $S$. haematobium among school children in Keffi in which males had a prevalence of $15.0 \%$ compared to $15.5 \%$ among females. This result is at variance with Mugono et al. [29] who reported that the prevalence of $S$. mansoni did not differ by sex [female: $65.80 \%$ and males: $61.65 \%$ ] among school children in Ukara Island, North-Western Tanzania. The high prevalence of the infection in males than females were probably due to the high exposure since they spent most of their time outside participating in activities that they came into contact with the diseases. Most females were found to spend fewer hours outside than their males' counterpart [25].

The results of this study showed that infection increases with age among school-aged pupil in the study area. This agrees with Iboyi et al. [23] who reported higher infection [20.3 \%] in children $>18$ years in Katsina-Ala, Benue State, while those within ages $3-7$ had $12.1 \%$ infection. The higher infection among pupils of ages 15 to 16 years in this study is in agreement with Ladan et al. [31] whose finding showed that persons within the age range of 10 - 19 years had the highest prevalence of $63.51 \%$, followed by $0-9$ years [42.76 \%]. However, this result is contrary to Mugono et al. [29] who reported that the prevalence decreased with increased age of the school children, with the youngest age group [4 - 10 years] having the highest prevalence [70.51\%] while the age 11-15 years having the lowest [55.41 $\%]$ prevalence. This could probably due to the degree of exposure and engagement in many outdoor activities including swimming and fishing due to the youthful exuberance. However, studies show that the distribution of schistosomiasis could be attributed to the fact that infection is easily established when the body is more frequently expose to contaminated water compared to the situation where such water is orally ingested.

The highest infection among pupils using streams while the least infection among pupil who used well as their source of drinking water in the study area is in agreement with Nanvyat et al. [33] who reported $58 \%, 54.6 \%$ and $43.8 \%$ infections among those utilized streams, rivers and well respectively as their basic water sources. Obadiah et al. [10] also recorded the highest prevalence [40.2 \%] in children who used water from streams/rivers in their homes, while the lowest was [3.4\%] was among those who used tap/borehole water. This is probably because streams provide grasses and shrubs which serve as suitable substrate snail vectors, hence encourage rapid increase in population of snails with subsequent increase in cercarial load. There was no pipe-borne water in the study area and this has led to the frequent used of streams, rivers by the majority of the inhabitants in the study area, hence the current prevalence of schistosomiasis.

The slightly higher prevalence of microhaematuria and proteinuria of $21.13 \%$ and $16.20 \%$ respectively than the $15.49 \%$ obtained from the microscopy indicates that microhaematuria and proteinuria are the most accurate and reliable indirect diagnostic method. This is as a result of its high specificity for negative results and high positive predictive value for positive results. The high sensitivity values reflect the usefulness of these diagnostic indices as morbidity indicators of S. haematobium in an endemic area [34]. It is also worth mentioning that a combination of microscopy, proteinuria and microhaematuria may be more efficient in infection diagnosis than a single variable. The prevalence of microhaematuria and proteinuria obtained in this study was lower than the $80 \%$ and $56 \%$ respectively reported in Ikpeshi in Akoko Edo LGA, Edo State (25); $80.3 \%$ and $24.8 \%$ proteinuria and microhaematuria respectively in Ijoun, Ogun State [34]; $65 \%$ microhaematuria in Akinlalu and Ogbogba communities, Osun State [35]; Ekanem et al. [36] reported decline in the microhaematuria and proteinuria [65.4 \% to $23.6 \%$ and $53.3 \%$ to $54.5 \%$ respectively] amongs in school children in Adim community in Cross River State eight years following the provision of portable water. The prevalence of schistosomiasis was $14.5 \%$ compared to $51 \%$ in the prepotable water era.

\section{Conclusion}

It's evident from the result that the prevalence of schistosomiasis in the study area needs proper and urgent attention as a health problem. The inability to create awareness to the target groups most especially children, adolescents/young adults on the basic knowledge of the disease, vectors, cause, sources of infection and prevention are major factors fascilitating its endemicity. This is important because primary school children for instance, are used to micturating and defecating in water bodies which aids the spreading of the disease. However, using 
microhaematuria and proteinuria as detected by reagent strips is practically-cheap, fast and easy to use in estimating the prevalence of S.haematobium infection. This can be used in Primary Health Care [PHC] setting with limited resources to screen and monitor $S$. haematobium infection in endemic areas. The following measures are therefore recommended to prevent the spread of schistosomiasis in the study area and other places: 1 . The establishment of modern health centres and the provision of portable water sources will play an important role in checking the spread of the disease; 2 . More funds should be put into research on the disease by the government and international bodies like World Bank and WHO for the development of vaccines; 3. Proper health education on the mode of infection and effects will play an important role in eradicating the disease. Construction of boreholes and good toilet facilities will help to reduce the infection.

\section{Compliance with ethical standards}

\section{Acknowledgments}

All authors would gratefully thank the Langtang North Local Government Education Board for approval to carry on the study and the Head Teacher, staff and pupils of each school for their support in the implementation of this study.

\section{Disclosure of conflict of interest}

The author declares no conflicts of interest. The author had no financial grants or external fund.

\section{Statement of ethical approval}

This study was ethically approved by the Local Government Education Board.

\section{Statement of informed consent}

Informed consent was obtained from all individual participants included in the study

\section{References}

[1] Center for Disease Ccontrol. (2018). The Burden of Schistosomiasis (Schisto, Bilharzia, Snail Fever).

[2] World Health Organization. (2018). Schistosomiasis

[3] Pan American Health Organization. (2014a). Schistosomiasis regional meeting. Defining a road map toward verification of elimination of schistosomiasis transmission in Latin America and the Caribbean by 2020.

[4] Berry A, Fillaux J, Martin-Blondel G, Boissier J, Iriart X, Marchou B, Magnaval F and Delobel P. (2016). The study of Berry et al. reports a single case of acute infection of urinary schistosomiasis probably acquired through bathing in the Cavu River in Corsica in summer 2015. It was the first reported case in Corsica with exposure in 2015. European Centre for Disease Prevention and Control.

[5] Grobusch M, Mühlberger N, Jelinek T, Bisoffi Z, Corachan M, Harms G, Matteelli A, Fry G, Hatz C, Gj $\varphi$ rup I, Schmid M, Knobloch J, Puente S, Bronner U, Kapaun A, Clerinx J, Nielsen LN, Fleischer K, Beran J, da Cunha S, Schulze M, Myrvang B and Hellgren U. (2003). Imported Schistosomiasis in Europe: Sentinel Surveillance Data from TropNetEurop. Journal of Travel Medicine, 10(3), 164-169.

[6] Lingscheid ST, Kurth F and Zoller T. (2010) Schistosomiasis imported to Europe: Analysis of 13 years Tropnet surveillance data. Department of Infectious Diseases and Pulmonary Medicine, Charité - Universitätsmedizin Berlin, Germany.

[7] Tamomh AG, Yousfi SR, Abakar, AD and Nour BYM. (2018). Prevalence of intestinal schistosomiasis among basic School Children in White Nile Sugar Scheme a new irrigated project, White Nile State, Sudan. Biol Med (Aligarh).

[8] Abdulkareem BO, Habeeb KO, Kazeem A, Adam AO and Samuel UU. (2018). Urogenital Schistosomiasis among School children and the Associated Risk Factors in Selected Rural Communities of Kwara State, Nigeria. Journal of Tropical Medicine.

[9] Dawaki S, Al-Mekhlafi HM, Ithoi I, Ibrahim J, Abdulsalam AM, Abdulhamid Ahmed A, Sady H, Atroosh WM, AlAreeqi MA, Elyana FN, Nasr NA and Surin J. (2016). Prevalence and risk factors of schistosomiasis among Hausa communities in Kano State, Nigeria. Revista do Instituto de Medicina Tropical de São Paulo, 58, 54. 
[10] Obadiah HI, Idu ME, Omudu EA, Shenge MF, Ameh MO and Mwakyoga A. (2018). Studies on Schistosoma haematobium infection in school-aged children in some parts of Benue State, Nigeria. Nigerian Journal of Parasitology, 39(1), 48 - 52.

[11] Nwabueze AA and Opara KN. (2007). Outbreak of Urinary Schistosomiasis among School Children in Riverine Communities of Delta State, Nigeria: Impact of Road and Bridge Construction. Journal of Medical Sciences, 7, 572-578.

[12] Akinwale O, Ajayi M, Akande D, Adeleke M, Gyang P, Adeneye A and Dike A. (2009). Prevalence of Schistosoma haematobium Infection in a Neglected Community, South Western Nigeria. International Journal of Health Research, 2(2), 149-155.

[13] Ezeh CO, Onyekwelu KC, Akinwale OP, Shan L and Wei H. (2019). Urinary schistosomiasis in Nigeria: a 50 year review of prevalence, distribution and disease burden. Parasite, 26, 19.

[14] Dawet A, Yakubu DY, Longmut R, Benjamin CB, DABURUM YH and Nannim N. (2012). Prevalence and intensity of Schistosoma haematobium among residents of Gwong and Kabong in Jos North Local Government Area, Plateau State, Nigeria. International Journal of Biological and Chemical Sciences, 6(4), 1557-1565.

[15] Banwat ME, Ogbonna C, Daboer JC, Chingle MP, Envuladu EA, Audu S and Lar LA. (2012). Prevalence of urinary schistosomiasis in school-aged children in Langai, Plateau State: pre- and post-intervention. Niger Journal of Medicine, 21(2), 146 - 149.

[16] Istifanus WA, Chinedu AF, Panda SM, Kela SL and Samaila AB. (2018). Intestinal schistosomiasis among some inhabitants of Bassa Local Government Area of Plateau State, Central Nigeria. Science Forum (Journal of Pure and Applied Sciences), 15, $40-45$.

[17] Nordqvist C. (2018).What is bilharzia, snail fever, or schistosomiasis?

[18] Pan American Health Organization. (2014b). Countries of the Americas aim to halt transmission of schistosomiasis by 2020.

[19] Cheesbrough M. (2002). District Laboratory practice in Tropical Countries. Part 2 Cambridge University Press: Cambridge, UK, 105-112.

[20] Harrison TR, Engene B, Kurt JI, Robert GP, Joseph BM and Anthony SF. (1987).Principles of Internal Medicine, publication. McGraw Hill Book Co., 1, 810-814.

[21] Nnoruka VC. (2000). Epidemiological Studies of Urinary schistosomiasis. Nigerian Journal of Parasitology, 21, 21-32.

[22] Onwe SO, Ani OC, Uhuo CA, Onwe CS and Odikamnoro 00. (2016). Pan American Studies of Urinary Schistosomiasis amongst School Age Children in Ebonyi North Senatorial District of Ebonyi State, Nigeria. International Journal of Tropical Disease \& Health, 18(3), 1-7.

[23] Iboyi MO, Onekutu A and Amuta EU. (2018). Prevalence and risk factors of urinary schistosomiasis among school children in Katsina-Ala Local Government Area of Benue State, Nigeria. European Journal of Pharmaceutical and Medical Research, 5(11), 499-506.

[24] Abdullahi MK, Bassey SE and Oyeyi TI. (2011). The epidemiology of Schistosoma haematobium infections in the 44 Local Government Areas of Kano State, Nigeria. Nigerian Journal of Parasitology, 32(1), 19 - 24.

[25] Nwele DE, Afiukwa EN, Uhuo CA, Ibiam GA and Agumah NB. (2017). Human water contact activities and associated urogenital schistosomiasis in Nkalagu community, Ebonyi State, Nigeria. Nigeria Journal of Parasitology, 38(2), 153 - 158.

[26] Nmorsi OPG, Egwunyenga OA, Ukwandu NCD and Nwokolo NQ. (2005). Urinary schistosomiasis in a rural community in Edo State, Nigeria: Eosinophiluria as a diagnostic marker. African Journal of Biotechnology, 4(2), $183-186$.

[27] Hajissa K, Muhajir AMA, Eshag HA, Alfadel A, Nahied E, Dahab R, Ali SM, Mohammed M, Gaafar M and Mohamed Z. (2018). Prevalence of schistosomiasis and associated risk factors among school children in Um-Asher area, Khartoum.

[28] Okwori1 AEJ, Sidi M, Ngwai YB, Obiekezie SO, Makut MD, Chollom SC, Okeke IO and Adikwu TI. (2014). Prevalence of Schistosomiasis among Primary School Children in Gadabuke District, Toto LGA, North Central Nigeria. British Microbiology Research Journal, 4(3), 255-261. 
[29] Mugono M, Konje E, Kuhn S, Mpogoro FJ, Morona D and Mazigo HD. (2014). Intestinal schistosomiasis and geohelminths of Ukara Island, North-Western Tanzania: prevalence, intensity of infection and associated risk factors among school children. Parasites \& Vectors, 7, 612.

[30] Munisi DZ, Buza J, Mpolya EA, Safari M and Kinung'hi SM. (2016). Intestinal Schistosomiasis among Primary Schoolchildren in Two On-Shore Communities in Rorya District, Northwestern Tanzania: Prevalence, Intensity of Infection and Associated Risk Factors. Journal of Parasitology Research.

[31] Ladan MU, Abubakar U, Abdullahi K, Bunza MDA, Nasiru M and Ladan MJ. (2011). Gender and age-specific prevalence of urinary schistosomiasis in selected villages near a dam site in Gusau Local Government Area, Zamfara State, Nigeria. Nigerian Journal of Parasitology, 32(1), 55 - 59.

[32] Ishaleku D, Yako AB, Usman D and Azamu SA. (2012). Schistosoma haematobium Infections among school children in Keffi Town, Nasarawa State, Nigeria. Scholarly Journal of Medicine, 2(7), 104-107.

[33] Nanvyat N, Dakul DA and Mwansat GS. (2011). Schistosomiasis in Ndinjor district of Langtang North Local Government Area of Plateau State, Nigeria. Nigerian Journal of Parasitology, 32(2), 209 - 213.

[34] Morenikeji O, Quazim J, Omoregie C, Hassan A, Nwuba R, Anumudu C, Adejuwon S, Salawu O, Jegede A and Odaibo A. (2014). A cross-sectional study on urogenital schistosomiasis in children; haematuria and proteinuria as diagnostic indicators in an endemic rural area of Nigeria. African Health Sciences, 14(2), 390396.

[35] Babatunde TA, Asaolu SO and Sowemimo OA. (2013). Urinary schistosomiasis among pre-school and school aged children in two peri-urban communities in Southwest Nigeria. Journal of Parasitology and Vector Biology, 5(7), $96-101$.

[36] Ekanem EE, Akapan FM and Eyong ME. (2018). Urinary schistosomiasis in school children of a southern nigerian community 8 years after the provision of potable water. Niger Postgraduate Medical Journal [serial online] 2017 [cited 2018 Dec 24], 24, 201-4.

\section{How to cite this article}

Dawet A, Bulus E, Joachim BN, Lumi EB and Yakubu DP. (2019). Schistosomiasis among primary school pupils in Pilgani Distric, Langtang North Local Government Area, Plateau State, Nigeria. GSC Biological and Pharmaceutical Sciences, 9(1), 05-14. 